\title{
COLHEITA E ARMAZENAMENTO DE SEMENTES DE GABIROBA(Campomanesia adamantium Camb. - MYRTACEAE) E IMPLICAÇÕES NA GERMINAÇÃO ${ }^{1}$
}

\author{
SAULO JOSÉ MELCHIOR² ${ }^{2}$ CECI CASTILHO CUSTÓDIO ${ }^{3}$ TADEUALCIDES MARQUES ${ }^{3}$, NELSONBARBOSAMACHADO NETO³
}

RESUMO - O objetivo deste trabalho foi estudar o comportamento de sementes de gabiroba em relação ao ponto de colheita, armazenamento e implicações na germinação. Para caracterização e ponto de colheita foram avaliados frutos de sete plantas, determinando-se o diâmetro, massa fresca de casca, polpa e sementes, número de sementes por fruto, graus Brix da polpacorrigidos para $20^{\circ} \mathrm{C}$ e germinação das sementes recém colhidas, sem retirada da mucilagem. O estudo do armazenamento compreendeu o experimento um, onde foram comparados os seguintes tratamentos: sementes frescas postas para germinar imediatamente após a retirada da mucilagem e outras armazenadas em frasco de vidro fechado a $25^{\circ} \mathrm{C}$ e a $8^{\circ} \mathrm{C}$ e em saco de papel a $25^{\circ} \mathrm{Ce} 60 \% \mathrm{UR}$, por 30 dias. $\mathrm{O}$ experimento dois (resistência à dessecação) consistiu na instalação diária da germinação (por cinco dias) e na verificação do grau de umidade das sementes mantidas em ambiente de laboratório $\left(25^{\circ} \mathrm{C}\right.$ e $\left.60 \% \mathrm{UR}\right)$, considerando-se como testemunha as sementes frescas (primeiro dia), logo após a retirada da mucilagem. No experimento três, os frutos foram armazenados por 20 dias: a temperatura média de $25^{\circ} \mathrm{C}$, dentro de uma vasilha de louça coberta com uma peneira; em saco de polietileno a $8^{\circ} \mathrm{C}$ e a $-18^{\circ} \mathrm{C}$. As sementes frescas, de frutos não armazenados, foram consideradas a testemunha. Os tratamentos foram avaliados pela germinação $\left(25^{\circ} \mathrm{C}\right)$, índice de velocidade de germinação e determinação do grau de umidade. O ponto de colheita de frutos de Campomanesia adamantium, para obtenção de sementes, pode ser determinado pela medida do Brix da polpa, indicando-se a colheita dos frutos com no mínimo, $15,75^{\circ}$ para se obter $95 \%$ de germinação. As sementes de guabiroba indicam que a espécie pode ser classificada como recalcitrante, por não suportarem armazenamento a baixa temperatura e nem a dessecação; o armazenamento em frasco de vidro fechado a $25^{\circ} \mathrm{C}$ mantém as sementes com $60 \%$ de germinação, por 30 dias. Todavia, a semeadura logo após a extração dos frutos, permite índices de germinação de, no mínimo, $74 \%$.

Termos para indexação: fruto do cerrado, conservação de sementes, qualidade fisiológica.

\section{HARVESTING AND STORAGE OF GABIROBA(Campomanesia adamantium Camb. - MYRTACEAE) SEEDS AND THEIR IMPLICATION IN THE GERMINATION}

\begin{abstract}
The aim of this study was to investigate the gabiroba seed behaviour regarding the harvesting point, storage and their implications in germination. For characterization and harvest point, fruits of seven plants were evaluated for diameter, peel, pulp and seed fresh matter, number of seeds per fruit, Brix degrees of pulp corrected to $20^{\circ} \mathrm{C}$ and extracted seed germination, with mucilage. The storage study was made up of three experiments. In the first experiment the following treatments were compared with fresh seeds: immediately after the mucilage removal, a second one stored in glass jars at $25^{\circ} \mathrm{C}$, another at $8^{\circ} \mathrm{C}$ and the last in paper bag at $25^{\circ} \mathrm{C}$ and $60 \% \mathrm{RH}$, during 30 days. The second experiment (resistance to desiccation) was done by germinating seeds left at $25^{\circ} \mathrm{C}$ and $60 \% \mathrm{RH}$ during five days, and moisture determination considering fresh seeds as control. For the third experiment, the fruits were stored for 20 days as follows: at room temperature $\left(25^{\circ} \mathrm{C}\right)$ in
\end{abstract}

\footnotetext{
${ }^{1}$ Submetido em 16/12/2005. Aceito para publicação em 31/07/2006. Parte da Dissertação de Mestrado do primeiro autor apresentada a UNOESTE;

${ }^{2}$ Eng. Agrônomo, pós graduando do Programa de Pós-Graduação em
}

Agronomia da UNOESTE, saulomelchior@hotmail.com;

${ }^{3}$ Eng. Agrônoma, Dra., Professora do Departamento de Biologia Vegetal e Fitossanidade da UNOESTE, Presidente Prudente - SP, CEP: 19067175. ceci@unoeste.br. 
a ceramic bowl covered by a nylon mesh; in polyethylene bags at $8^{\circ} \mathrm{C}$ and at $-18^{\circ} \mathrm{C}$. Fresh seeds, from non-stored fruits, were used as control. Treatments were evaluated by germination $\left(25^{\circ} \mathrm{C}\right)$, germination speed index (IVG) and moisture determination. It was concluded that the fruit harvest point might be determined by the Brix degrees of the pulp and it was indicated that fruit would be harvested with at least $15,75^{\circ}$ to obtain $95 \%$ of germination. Campomanesia adamantium seed behaviour showed that the species must be classified as recalcitrant, either by not supporting storage or by not tolerating desiccation. The storage in tightly closed glass jars at $\left(25^{\circ} \mathrm{C}\right)$ maintained the germination at $60 \%$, for 30 days. However, sowing the seeds, immediately after the extraction from the fruits gave germination indexes of at least $74 \%$.

Index terms: cerrado fruit, seed conservation, physiological quality.

\section{INTRODUÇÃO}

A região de domínio do bioma Cerrado compreende uma área extensa e contínua nos Estados de Goiás, Bahia, Minas Gerais, Mato Grosso e algumas penínsulas e áreas disjuntas que se estendem por outros Estados (Eiten, 1972). No Estado de São Paulo, o Cerrado apresenta-se na forma de manchas dispersas, que ocupavam originalmente cerca de $14 \%$ do território (São Paulo, 1997). Mais recentemente, Kronka et al. (1998) observaram, em imagens de satélite de 1992, a rápida destruição desse bioma no Estado, encontrando uma área total remanescente de apenas $2.379 \mathrm{~km}^{2}$, quando comparada com a área de $33.929 \mathrm{~km}^{2}$ no ano de 1962 , registrada por Borgonovi e Chiarini (1962).

Diante da destruição dessa cobertura vegetal original e levando-se em consideração que muitas espécies do Cerrado são produtoras de frutas (Parente e Machado, 1989ab; Silva et al., 1994) e têm características organolépticas interessantes, que as classificam como economicamente potenciais, vê-se a necessidade de estudos que ampliem o conhecimento e indiquem novas opções para potencializar a sua exploração.

Entre as espécies de Cerrado do interior do Estado de São Paulo, quando se considera o estrato inferior (diâmetro do caule inferior a $5 \mathrm{~cm}$ ), um estudo de Durigan et al. (2002) realizado em Brotas/SP mostrou que a Campomanesia adamantium é a espécie que apresentou maior densidade relativa entre as 61 espécies identificadas, de 32 famílias botânicas, atingindo 2.202 indivíduos por hectare.

A propagação de espécies vegetais mais natural é aquela que ocorre por meio de sementes, de estacas de caule ou de raízes. No caso da gabiroba, alguns estudos vêm sendo realizados com relação à propagação por sementes, no entanto, o desenvolvimento lento das plântulas e a predação intensa de frutos, estão entre as principais limitações ao cultivo (Leitão e Martins, 1981).
Poucos estudos avaliaram a germinação e a conservação das sementes de plantas do gênero Campomanesia. Alguns indicaram que sementes de Campomanesia rufa (Berg) Mied. germinaram bem $(>90 \%)$ e que se conservaram por 180 dias, em sacos de plástico de polietileno à temperatura ambiente $\left(23-35^{\circ} \mathrm{C} ; 70-75 \% \mathrm{UR}\right)$. A refrigeração foi inadequada à conservação dessa espécie (Arrigoni et al., 1997).

Ao submeterem sementes de gabiroba da espécie Campomonesia lineatifolia Ruiz et Pav. ao dessecamento e à baixa temperatura, Carvalho et al. (1997) verificaram que a redução do grau de umidade para $19,0 \%$, não afetou a porcentagem final de germinação, a qual só começou a decrescer quando a umidade foi reduzida para $16,0 \%$, culminando com a perda total da capacidade de germinação, quando atingiram $8,1 \%$ de teor de água. A redução do grau de umidade das sementes para menos de $30 \%$ causou o retardamento e a desuniformidade da germinação, com correlação negativa entre o grau de umidade e o tempo médio de germinação e positiva entre o grau de umidade e o coeficiente de uniformidade da germinação. As sementes tornaram-se inviáveis quando foram expostas a temperaturas de $4,0^{\circ} \mathrm{C}$, por período igual ou superior a 12 horas. Esses resultados indicaram que sementes de Campomonesia lineatifolia têm comportamento recalcitrante, não suportando a dessecação e o armazenamento em temperatura baixa.

Sementes recalcitrantes ou não anidrobióticas (Hoekstra et al., 2001) são intolerantes à dessecação, até graus de umidade entre 15 e 20\% (Roberts, 1973; Hong e Ellis, 1992). Embora, por definição, a secagem de sementes recalcitrantes resulte no declínio da viabilidade, considerável variação na sensibilidade à dessecação tem sido reportada. Considerando essa variação, Farrant et al. (1988) propuseram a separação das sementes recalcitrantes em "altamente", "moderadamente" e "minimamente" recalcitrantes.

O objetivo deste trabalho foi verificar o comportamento 
de sementes de Campomanesia adamantium em relação ao ponto de colheita, armazenamento e implicações na germinação.

\section{MATERIAL E MÉTODOS}

Na região de Cerrado do município de Rancharia, Estado de São Paulo, com altitude de $515 \mathrm{~m}$, situada à latitude $22^{\circ} 13^{\prime} 35^{\prime}$ 'sul e à longitude de $50^{\circ} 50^{\prime} 35^{\prime}$ 'oeste, foram coletadas, na primeira quinzena de dezembro de 2003, na Fazenda Santo André, numa área de 14,5ha, num raio de 100 metros ao redor de ponto pré-estabelecido marcado com estaca, frutos de gabiroba, Campomanesia adamantium, considerados maduros por apresentarem coloração verde levemente amarelada. Os frutos foram colhidos de sete plantas, considerando-se as características agronômicas como boa arquitetura, porte baixo e produção, para a caracterização dos frutos e sementes. Esses frutos foram acondicionados, separadamente, em quatro embalagens plásticas constituindo repetições de 20 frutos por planta. Outros frutos, aproximadamente 1600 , foram colhidos em diferentes pontos do campo para realização dos experimentos um e dois do estudo de armazenamento e das implicações na germinação.

Caracterização de frutos e sementes: foi medido o diâmetro $(\mathrm{cm})$ dos frutos colhidos das sete plantas, utilizandose paquímetro, para a caracterização do tamanho. Os frutos inteiros de cada repetição foram pesados para determinação da massa fresca, em gramas. Em seguida, os frutos foram despolpados manualmente e com auxílio de pinça, separados em casca, semente e polpa, as quais foram pesadas separadamente, para obtenção da massa fresca de cada parte, em gramas.

As sementes de cada repetição foram contadas para determinar o número médio por fruto e calcular a massa média, em gramas, de cada uma. O total de sementes de cada repetição, oriundas de 20 frutos, foram postas para germinar, sobre papel, em caixas gerbox plásticas e transparentes, em germinador à $25^{\circ} \mathrm{C}$, com avaliações diárias, por 14 dias, para determinação da porcentagem de germinação (critério de protrusão da raiz primária até $0,5 \mathrm{~cm}$ ) das sementes recém extraídas dos frutos, com mucilagem.

Com a polpa dos frutos, de cada repetição, foi determinado o Brix, usando-se refratômetro óptico, e corrigindo-se o valor para a temperatura de $20^{\circ} \mathrm{C}$.

Armazenamento e germinação: os 1600 frutos colhidos foram separados em três tamanhos: grandes (diâmetro médio de 2,31cm e desvio padrão de 0,18 ); médios (diâmetro médio de $2,21 \mathrm{~cm}$ e desvio padrão de 0,33 ) e pequenos (diâmetro médio de $1,71 \mathrm{~cm}$ e desvio padrão de 0,19 ). Os frutos médios foram utilizados para a obtenção de sementes, por serem mais abundantes. A despolpa foi manual, com auxílio de pinça para o rompimento da casca, e a polpa com as sementes, foi posta em uma solução de $50 \mathrm{~mL}$ de hidróxido de amônio a $25 \%$, para fermentar por 48 horas para retirar a mucilagem (Carmona et al., 1994). Após esse período, as sementes acondicionadas em uma peneira plástica, foram lavadas em água corrente, secas superficialmente sobre uma toalha de papel, por 30 minutos, divididas em duas porções e utilizadas imediatamente para os experimentos um e dois, que foram instalados simultaneamente.

No experimento um, foram comparados os seguintes tratamentos: sementes frescas postas para germinar imediatamente após a retirada da mucilagem (F) e outras armazenadas em frasco de vidro fechado a $25^{\circ} \mathrm{C}$ (V25); em frasco de vidro fechado a $8^{\circ} \mathrm{C}(\mathrm{V} 8)$ e em saco de papel a $25^{\circ} \mathrm{C}$ e $60 \%$ UR $(\mathrm{P})$, por 30 dias.

Outra porção das sementes despolpadas foi submetida ao experimento dois (resistência à dessecação), que consistiu na instalação diária da germinação (por cinco dias) e na verificação do grau de umidade (Brasil, 1992). Durante o período as sementes foram mantidas em ambiente de laboratório $\left(25^{\circ} \mathrm{C}\right.$ e $\left.60 \% \mathrm{UR}\right)$ considerando-se como testemunha as sementes frescas (primeiro dia), logo após a retirada da mucilagem.

$\mathrm{Na}$ colheita subseqüente foram obtidos 1000 frutos extras, no mesmo local, para o experimento três (armazenamento de frutos). Os frutos médios foram armazenados por 20 dias: a temperatura média de $25^{\circ} \mathrm{C}$, dentro de uma vasilha de louça coberta com uma peneira (FA25); em saco de polietileno a $8^{\circ} \mathrm{C}(\mathrm{FA} 8)$ e a $-18^{\circ} \mathrm{C}(\mathrm{FA}-18)$. Ao fim do armazenamento os frutos foram despolpados e as sementes passaram pela fermentação e germinação, como descrito anteriormente. As sementes frescas, de frutos não armazenados, foram consideradas a testemunha.

De cada tratamento, foram colocadas para germinar quatro repetições com 25 sementes, sobre papel, em caixas gerbox, em germinador tipo Mangelsdorf à $25^{\circ} \mathrm{C}$, com 12 dias de avaliações diárias e calculados a porcentagem de germinação e do índice de velocidade de germinação - IVG (Nakagawa, 1999). Adotou-se o critério de protrusão da raiz primária até $0,5 \mathrm{~cm}$. O grau de umidade das sementes foi determinado em estufa a $105 \pm 3^{\circ} \mathrm{C}$ por $24 \mathrm{~h}$ com duas repetições (Brasil, 1992).

Procedimento estatístico: a caracterização de frutos e 
sementes foi conduzida em delineamento inteiramente casualizado, com quatro repetições por planta, com aplicação do teste $\mathrm{F}$ para análise da variância e, quando este foi significativo, as médias dos tratamentos (plantas) foram comparadas pelo teste de Tukey. Paralelamente, os dados obtidos dos 560 frutos, foram analisados por estatística descritiva através de distribuição em classes de freqüência.

Nos experimentos um, dois e três o delineamento experimental foi o inteiramente casualizado aplicando-se o teste $\mathrm{F}$, para análise da variância e, quando esta foi significativa, os tratamentos foram comparados pelo teste de Tukey (experimentos um e três) e análise de regressão polinomial e correlação linear com aplicação do teste $t$ no experimento
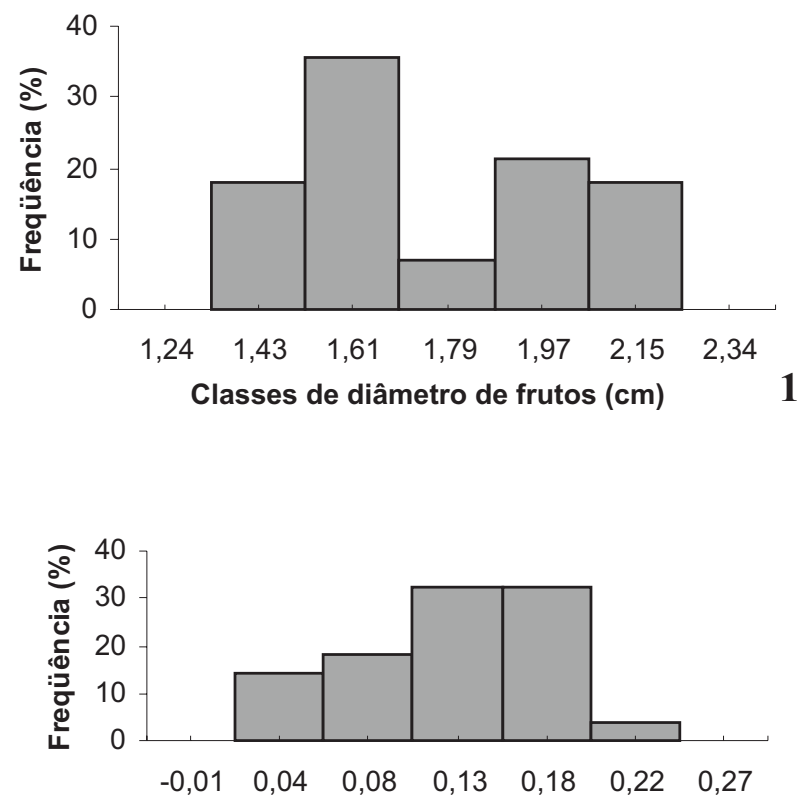

Classes de massa fresca de sementes $(g)$ dois. Os dados de germinação foram transformados em arco seno da raiz quadrada de x.100-1. Os dados de IVG e do grau de umidade não foram transformados. A análise dos dados foi feita com auxílio do programa estatístico SISVAR da Universidade Federal de Lavras.

\section{RESULTADOS E DISCUSSÃO}

\section{Caracterização de frutos e sementes}

$\mathrm{Na}$ Figura 1 os valores no eixo das abscissas indicam o ponto médio de cada classe, $35,7 \%$ dos frutos tinham diâmetro médio de $1,61 \mathrm{~cm}$ e $17,9 \%$ dos frutos $1,43 \mathrm{~cm}$, representando aproximadamente $54 \%$ dos frutos (Figura 1.1).
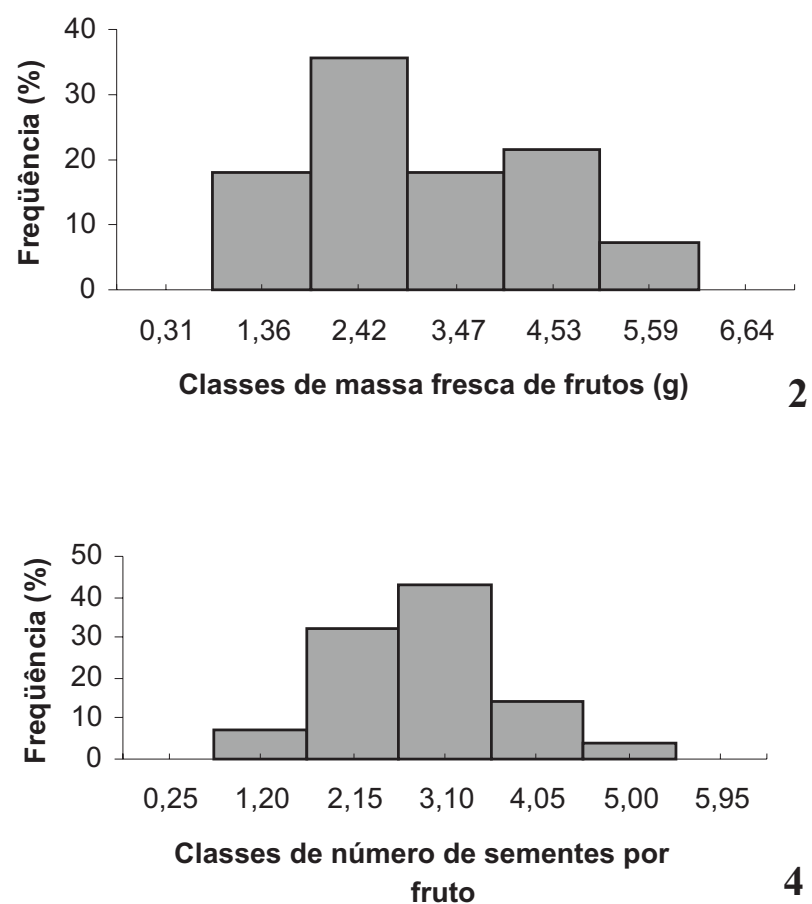

4

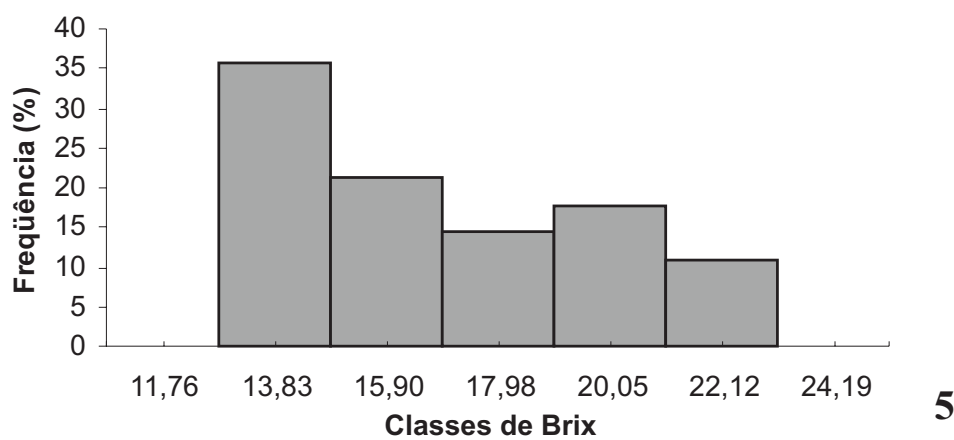

FIGURA 1. Distribuição de classes de freqüência, através da estatística descritiva de frutos e sementes de gabiroba: diâmetro de frutos (1); massa fresca de frutos (2); massa fresca de cada semente (3); número de sementes por fruto (4) e Brix corrigido para $20^{\circ} \mathrm{C}(5)$. Presidente Prudente, 2003. 
A classe de frutos com diâmetro médio de aproximadamente $1,79 \mathrm{~cm}$ foi a de menor representatividade, com apenas $7,1 \%$ dos frutos. As classes de freqüência, $1,97 \mathrm{~cm}$ e $2,15 \mathrm{~cm}$, representaram aproximadamente $39 \%$ dos frutos.

A massa fresca dos frutos de maior freqüência $(35,7 \%)$ foi de $2,42 \mathrm{~g}$ e a de menor freqüência $(7,1 \%)$ pesou $5,6 \mathrm{~g}$ (Figura 1.2). A massa fresca de cada semente (Figura 1.3) foi distribuída em: $32,1 \%$ das sementes com $0,13 \mathrm{~g}, 32,1 \%$ com $0,18 \mathrm{~g}$, mostrando que as duas classes juntas representavam $64,2 \%$ da amostra; $32 \%$ estavam na faixa de
0,04 a $0,08 \mathrm{~g}$ e apenas $3,5 \%$ das sementes pesavam, em média, $0,22 \mathrm{~g}$.

Analisando-se o número de sementes por fruto, observouse que $42,8 \%$ destes possuíam uma média de 3,1 sementes; $32,1 \%$ apresentaram 2,1 e 14,2\% apresentaram 4,0 (Figura 1.4). O Brix dos frutos (Figura 1.5) distribuiu-se em: $35,7 \%$ com $13,83^{\circ}$ Brix e $28,57 \%$ dos frutos exibiram 20,05 e $22,12^{\circ}$ Brix.

Na Figura 2, encontra-se a massa fresca dos frutos em gramas (1), distribuição relativa das partes em porcentagem
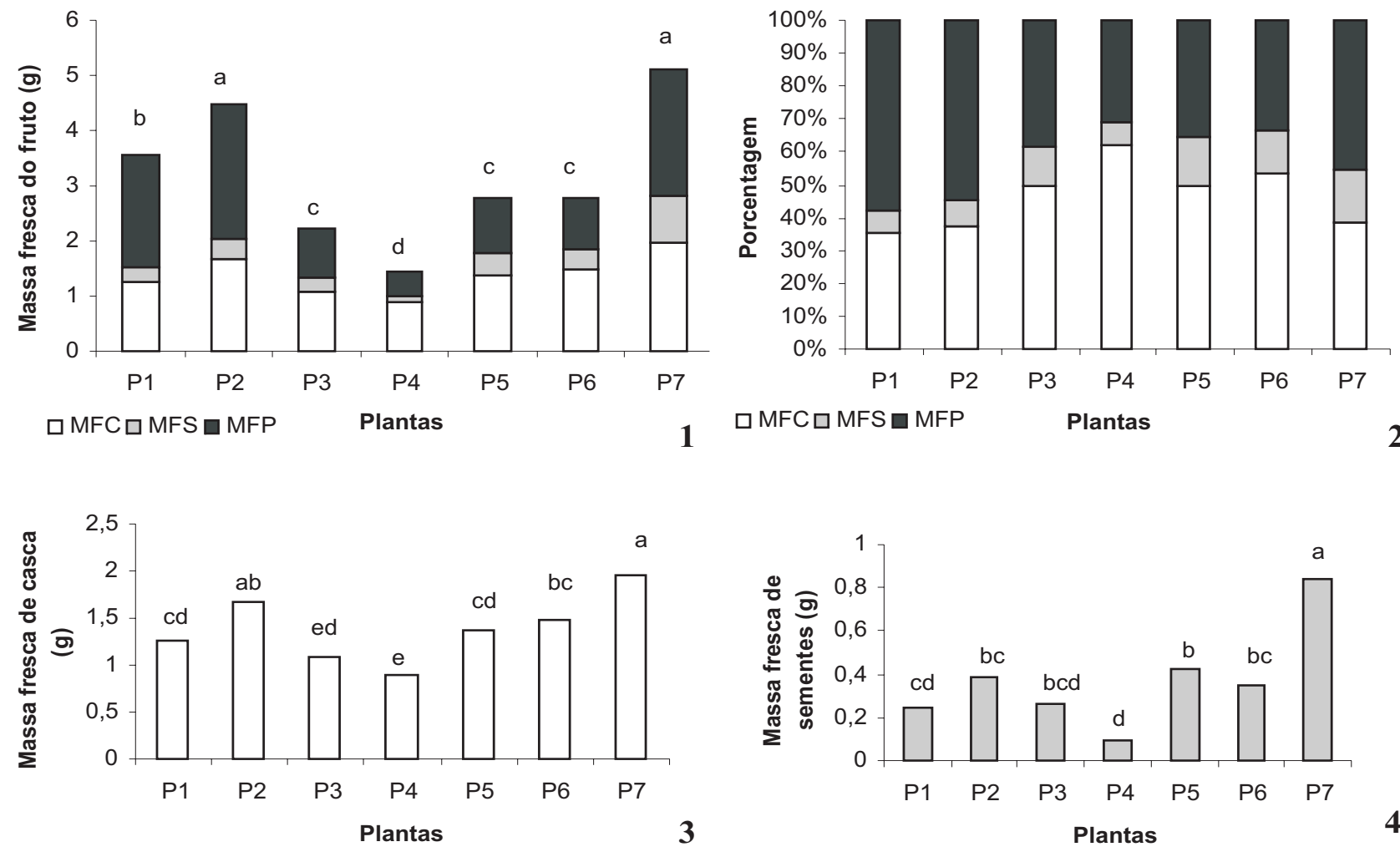

2

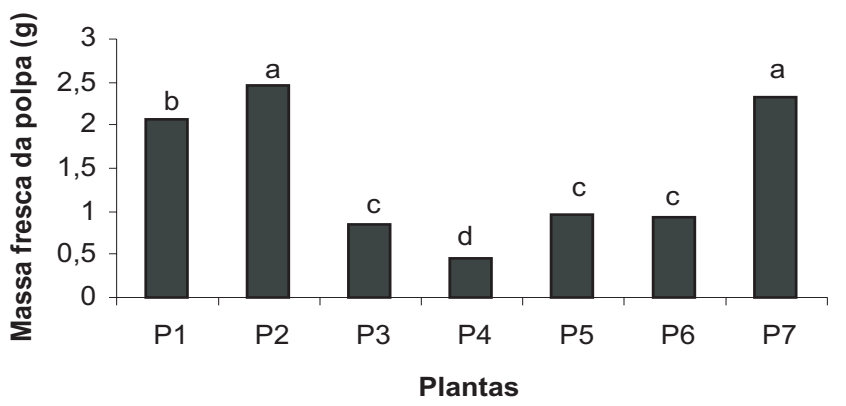

FIGURA 2. Massa fresca de frutos (1); distribuição relativa das partes (2) e massa fresca de casca MFC (3); massa fresca de sementes MFS (4) e massa fresca de polpa MFP (5), de sete plantas de gabiroba. Presidente Prudente, 2003. Barras seguidas por letras iguais indicam médias sem diferenças significativas, pelo teste Tukey, ao nível de $5 \%$. 
(2) e massa fresca de casca (3), sementes (4) e polpa (5). A comparação das características dos frutos, de diferentes plantas, indicou a existência de variabilidade e possibilidade de seleção de materiais promissores. As plantas 2 e 7 apresentaram a maior massa fresca de frutos, com valores médios entre 4,5 e 5,1g, enquanto a planta 1 apresentou 3,5g, sendo significativamente inferior às plantas 2 e 7 . As plantas 3, 5 e 6 apresentaram massa fresca em torno de 2,1 a $2,9 \mathrm{~g}$ e a planta 4 apresentou cerca de $1,5 \mathrm{~g}$, significativamente inferior as demais.

Com relação à distribuição relativa de massa fresca da casca, semente e polpa (Figura 2.2), pode-se notar que as plantas 1, 2 e 7 apresentaram uma maior porcentagem relativa de polpa em relação à casca. Em todas as plantas, a porcentagem relativa de sementes em relação ao todo foi pequena, 7,0 a $16,3 \%$.

Quando se analisou a massa fresca da casca (Figura 2.3), pode-se perceber que as plantas que apresentaram maior massa foram 2 e 7 , porém, a casca não representou proporção elevada no todo nessas plantas. Finalmente, a planta 4, com $0,9 \mathrm{~g}$, apresentou proporção de casca alta em relação ao todo.

A massa fresca da semente (Figura 2.4) mostrou que a planta 7 apresentou maior valor, $0,81 \mathrm{~g}$, enquanto a planta 5 apresentou 0,41g. As plantas 1, 2, 3 e 6 apresentaram valores entre 0,21 e $0,40 \mathrm{~g}$ e a planta 4 foi a que exibiu menor valor, $0,1 \mathrm{~g}$

A massa fresca da polpa (Figura 2.5) mostrou que as plantas 2 e 7 obtiveram valores entre 2,4 e $2,5 \mathrm{~g}$, enquanto a planta 1 apresentou aproximadamente $2,0 \mathrm{~g}$, sendo significativamente inferior às plantas 2 e 7 . As plantas 3,5 e 6 mostraram valores de massa fresca da polpa entre 0,8 e 1,0g, enquanto a planta 4 apresentou o menor valor, $0,5 \mathrm{~g}$.

Verificou-se que os frutos de maior diâmetro foram os das plantas 1, 2 e 7, que mediram entre 2,0 e 2,2 cm, seguidos pelos da planta 5 com aproximadamente $1,7 \mathrm{~cm}$ (Figura 3.1), os das plantas 3 e 6 entre 1,5 e 1,6cm e os da planta 4 que apresentaram os menores diâmetros, $1,4 \mathrm{~cm}$.

A análise do número de sementes por fruto (Figura 3.2) mostrou que a planta 7, com média de 4,5 sementes por fruto, foi a que apresentou o maior número, enquanto as plantas $3 \mathrm{e}$ 6 apresentaram 3,0 sementes por fruto e diferiram significativamente da planta 7 .

A porcentagem de germinação das sementes recém extraídas e com mucilagem (Figura 3.3) mostrou que aquelas provenientes das plantas 3, 4 e 5 germinaram $100 \%$, enquanto as das plantas 1, 2 e 7 entre 81 e $85 \%$, que porém não diferiram das sementes das plantas 3, 4 e 5 . As da planta 6
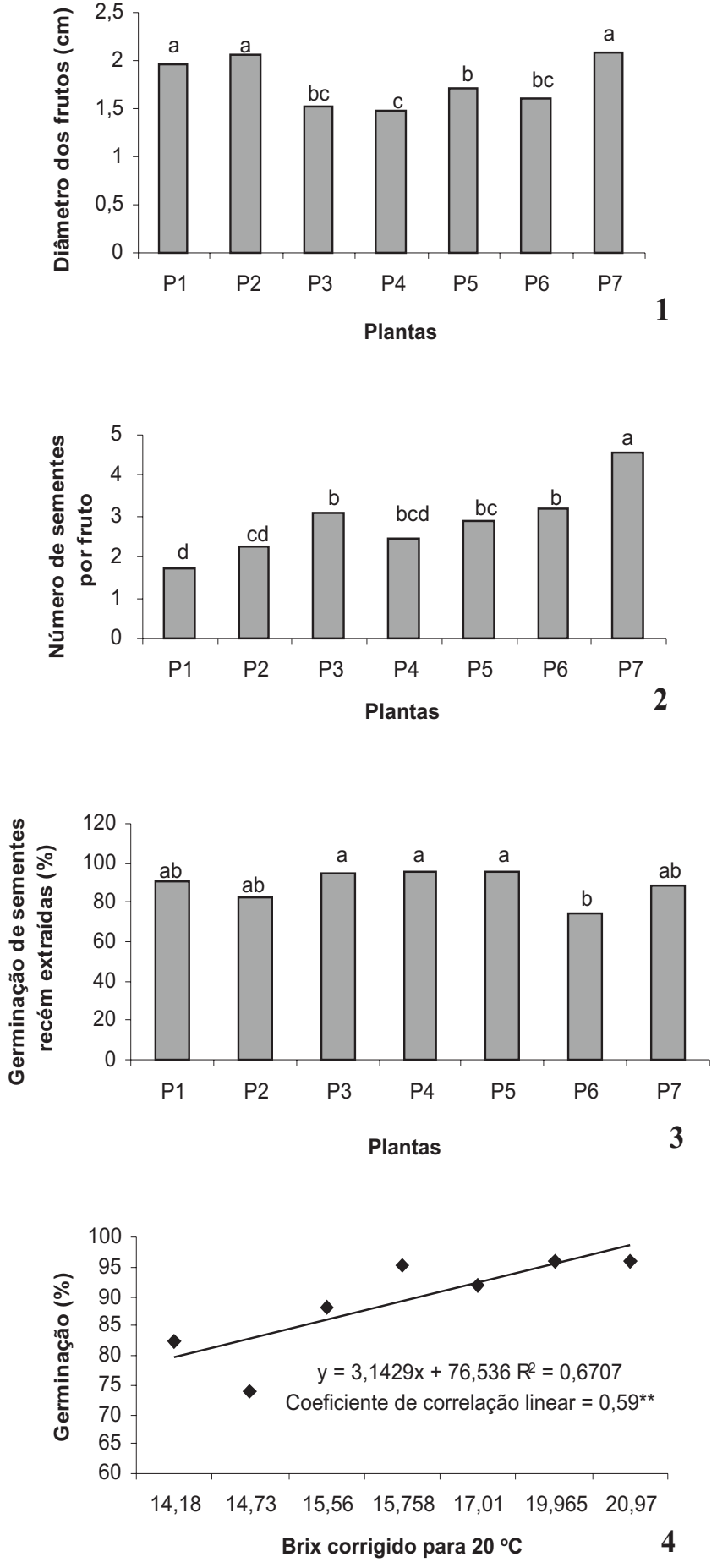

FIGURA 3. Diâmetro dos frutos (1); número de sementes por fruto (2); germinação das sementes recém extraídas (3) e relação Brix x germinação (4), de sete plantas de gabiroba. Presidente Prudente, 2003. Barras seguidas por letras iguais indicam médias sem diferenças significativas, pelo teste Tukey, ao nível de $5 \% . \mathbf{R}^{2}=$ coeficiente de determinação. $* *$ Coeficiente de correlação linear significativo pelo teste $t$ com $1 \%$ de significância. 
tiveram os menores índices de germinação.

A relação do grau Brix da polpa corrigido para $20^{\circ} \mathrm{C} \mathrm{com}$ a germinação (Figura 3.4), mostrou a tendência de aumento da porcentagem de germinação, de 80 para $100 \%$, quando o Brix passou de 14,18 para 20. Essa relação linear crescente significativa indicou que sementes colhidas de frutos mais maduros (polpa com maior concentração de açúcar) germinaram melhor. $\mathrm{O}$ Brix pode ser um parâmetro norteador do ponto de maturação dos frutos para colheita de sementes.

Outras correlações de interesse para o melhoramento foram avaliadas, como tamanho do fruto x germinação e número de sementes por fruto $\mathrm{x}$ germinação, porém não apresentaram significância. Todavia, pela caracterização geral apresentada pode-se afirmar que a espécie apresenta variabilidade para os principais componentes de produção.

\section{Armazenamento e germinação}

No experimento um (Figura 4.1) verificou-se que a germinação das sementes armazenadas em vidro fechado a $25^{\circ} \mathrm{C}$ (V25) e as semeadas frescas, imediatamente após a retirada da mucilagem $(\mathrm{F})$, apresentaram os maiores índices, atingindo médias de 60 e $45 \%$, respectivamente. O tratamento $\mathrm{V} 25$, ao final de 30 dias, estava, em parte, em início de germinação devido a manutenção do grau de umidade em torno de $28 \%$ (Figura 4.3). Apenas as sementes sem protusão da raiz primária foram utilizadas para instalação da germinação, porém é possível que tenha ocorrido 'priming' durante os 30 dias em que as sementes desse tratamento permaneceram na embalagem de vidro, explicando a vantagem numérica deste tratamento em relação às sementes frescas e a maior velocidade de germinação desse tratamento (Figura 4.2). Por permitir o início da germinação, essa forma de armazenamento é questionável. Os menores resultados de germinação (Figura 4.1) e IVG (Figura 4.2) foram obtidos pelas sementes armazenadas em saco de papel $32 \%(\mathrm{P})$ e pelas conservadas em vidro a $8^{\circ} \mathrm{C}$, que apresentaram germinação de $25 \%$ (V8).

As sementes em embalagem de vidro conservaram teores de água próximos àqueles das sementes frescas (Figura 4.3), indicando a eficiência da embalagem para a manutenção do teor de água da semente. Assim, as diferenças de germinação entre os tratamentos F, V25 e V8 não foram devido ao teor de água na semente.

Constatou-se que o ambiente a $8^{\circ} \mathrm{C}$ exerceu efeito negativo sobre a conservação das sementes de gabiroba, o que concorda com as afirmações de Carvalho et al. (1997) que dizem que sementes de Campomanesia lineatifolia perdem completamente a viabilidade quando expostas à temperatura de $4,0^{\circ} \mathrm{C}$, por um período igual ou superior a 12 horas. Hong e Ellis (1992), também chegaram a conclusão semelhante, confirmando que para a maioria das espécies vegetais de importância econômica, a viabilidade e o vigor das sementes podem ser conservados pelas reduções do teor
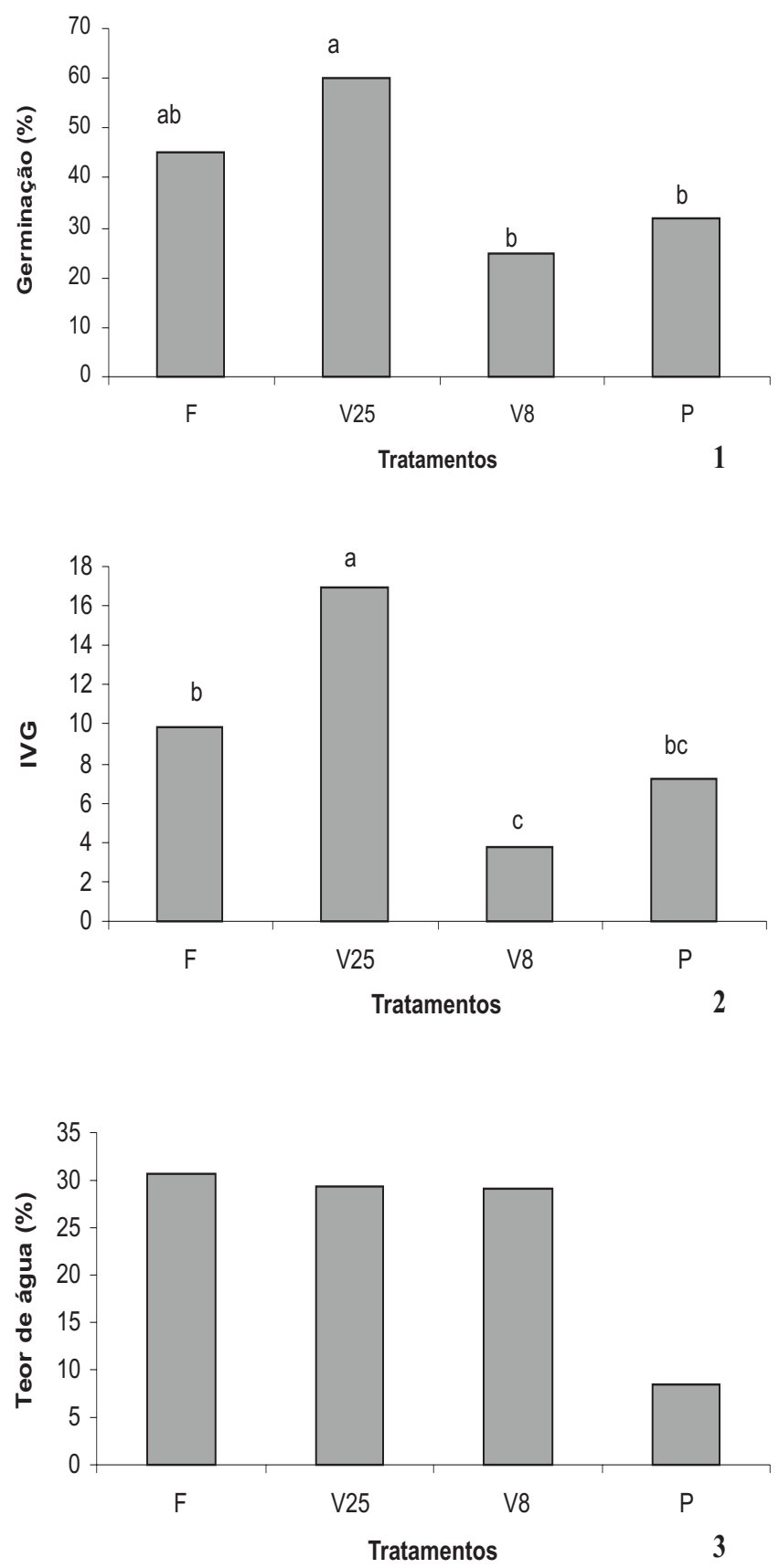

FIGURA 4. Porcentagem de germinação (1); índice de velocidade de germinação (2) e teor de água (3) de sementes de gabiroba frescas (F); armazenadas por 30 dias em frasco de vidro fechado a $25^{\circ} \mathrm{C}(\mathrm{V} 25)$; $8^{\circ} \mathrm{C}(\mathrm{V} 8) \mathrm{e}$ em saco de papel a $25^{\circ} \mathrm{C}$ e $60 \%$ UR (P). Presidente Prudente, 2003. Barras seguidas por letras iguais indicam médias sem diferenças significativas, pelo teste Tukey, ao nível de 5\%. 
de água da semente e da temperatura do ambiente, são as sementes ortodoxas. Porém, das 6.721 espécies, consideradas de importância econômica, 7\% possuem sementes que são recalcitrantes, além de serem sensíveis à dessecação, não toleram armazenamento a temperatura baixa, dificultando sua conservação por períodos prolongados (Fonseca e Freire, 2003).

Outro ponto a ser destacado é que as sementes armazenadas em vidro a $25^{\circ} \mathrm{C}$ conservaram o teor de água, enquanto as sementes em embalagem porosa não o fizeram. Esta diferença, na manutenção do grau de umidade da semente, proporcionou resultados diversos de conservação, pois, ao final de 30 dias, as sementes que foram mantidas com maior teor de água apresentaram maiores germinação e velocidade de germinação, estando, em parte, de acordo com Cícero et al. (1986). A conservação de sementes recalcitrantes, por longos períodos, não é alcançada por processos similares aos utilizados para as sementes ortodoxas, mormente a secagem. Sem a possibilidade de secagem, para a maioria das sementes recalcitrantes, os pesquisadores têm mantido as sementes com teor de água alto, com o acondicionamento em embalagens herméticas e a temperaturas baixas (Cícero et al., 1986). Maluf et al. (2003) relataram que a redução de água para 53\% permitiu a conservação dos diásporos de Eugenia involucrata DC., pertencente à mesma família da gabiroba, por até 180 dias, em câmara fria e em embalagens plásticas. No entanto, os resultados obtidos para gabiroba, nessa pesquisa, mostraram a impossibilidade de conservação em temperaturas baixas.

Na Figura 5 encontra-se a germinação, o IVG e o teor de água das sementes de gabiroba submetidas à avaliação de resistência à dessecação, após sua extração dos frutos. A

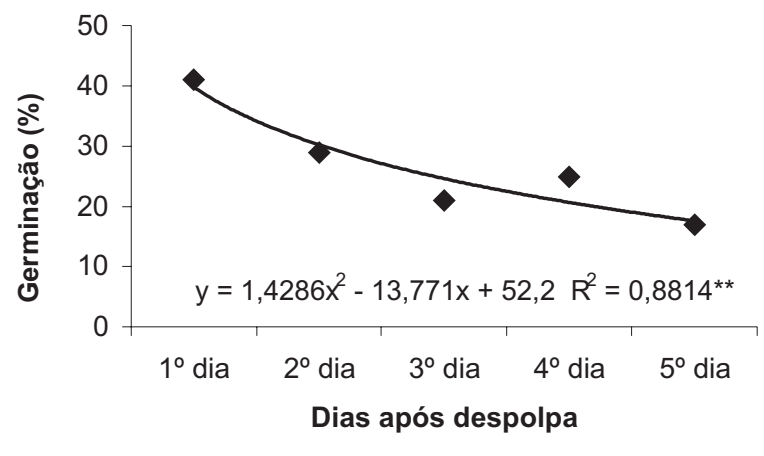

1
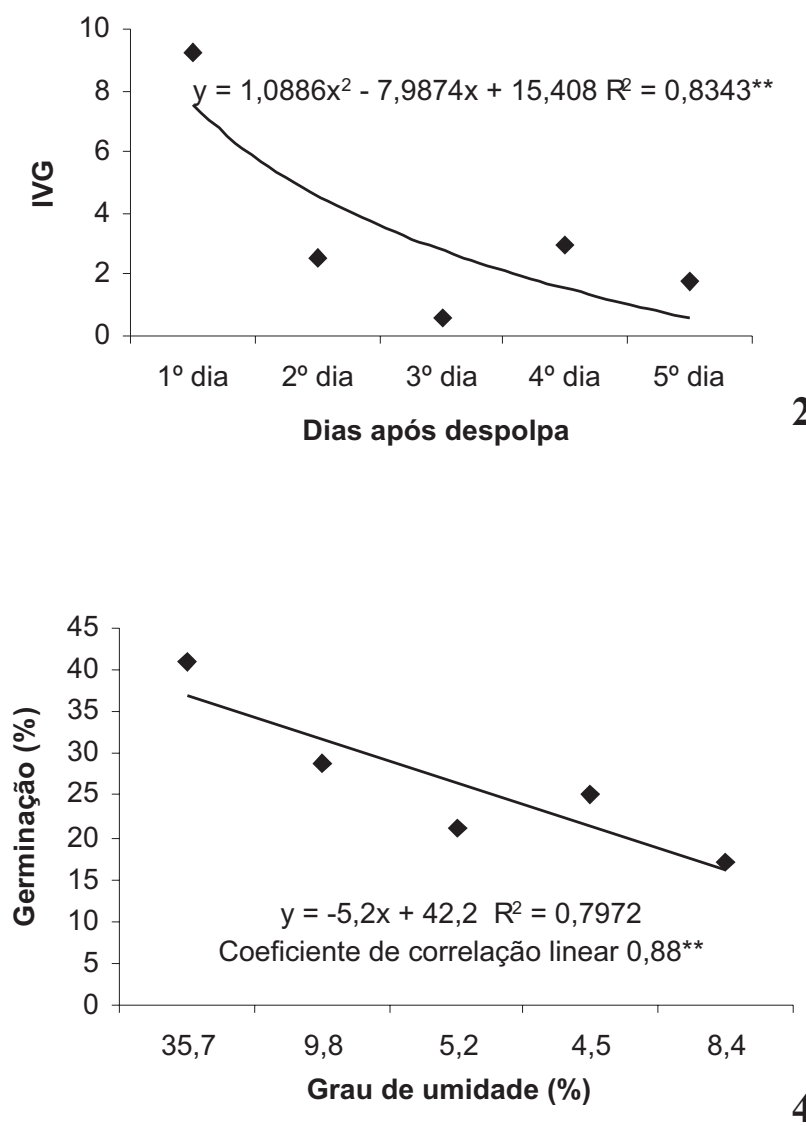

FIGURA 5. Porcentagem de germinação (1); índice de velocidade de germinação (2); teor de água (3) e correlação linear entre germinação $x$ teor de água (4), em sementes de gabiroba armazenadas em saco de papel, a $25^{\circ} \mathrm{C}$ e $60 \%$ UR, e colocadas para germinar no $1^{\circ}, 2^{\circ}, 3^{\circ}, 4^{\circ}$ e $5^{\circ}$ dia de armazenamento. Presidente Prudente, 2003 . $R^{2}=$ coeficiente de determinação. ** equação significativa, ao nível de $1 \%$, pelo teste $\mathbf{F}$ ou Coeficiente de correlação linear significativo pelo teste $t$. 
porcentagem de germinação (Figura 5.1) e o IVG (Figura 5.2) diminuíram continuamente na medida em que as sementes permaneceram mais dias expostas às condições ambientais. Quando se compararam esses resultados com os do gráfico da perda d'água (Figura 5.3), pode-se perceber que há uma relação direta entre esses parâmetros (Figura 5.4), ou seja, tanto a porcentagem de germinação quanto o IVG diminuem com o passar dos dias, assim como, a porcentagem de água nas sementes, mostrando que quanto mais se perde água com o decorrer do tempo, a redução da germinação é maior e quando esta ocorre é mais lenta. Confirmando as afirmações de Hong e Ellis (1992) que consideraram como recalcitrantes as sementes que reduzem a germinação quando atingem entre 15-20\% de água. Carvalho et al. (1997) verificaram que a redução do teor de água para $16 \%$ promoveu o decréscimo da germinação das sementes de Campomanesia lineatifolia.

As porcentagens de germinação e IVG das sementes de Campomanesia adamantium de sementes frescas de frutos não armazenados (F) e de frutos armazenados por 20 dias a $25^{\circ} \mathrm{C}$ (FA25), a $8^{\circ} \mathrm{C}(\mathrm{FA} 8)$ e a $-18^{\circ} \mathrm{C}$ (FA-18) estão na Figura 6. A idéia de manter as sementes nos frutos era evitar a dessecação, o que realmente aconteceu (as sementes frescas dos três tratamentos de frutos armazenados apresentaram 30\% de água, dados não apresentados), então a diminuição da germinação nos diferentes tratamentos não deve ser atribuída à dessecação, mas ao ambiente de armazenamento. No entanto, a qualidade das sementes não foi preservada quando os frutos foram armazenados a $25^{\circ} \mathrm{C}$, indicando que a continuidade da semente dentro do fruto, mesmo garantindo a manutenção da umidade, não garantiu a conservação da viabilidade. As sementes dos frutos armazenados a $8^{\circ} \mathrm{C}$ apresentaram germinação e IVG superiores àquelas armazenadas a $25^{\circ} \mathrm{C}$ e a $-18^{\circ} \mathrm{C}$ e inferior a germinação das sementes extraídas dos frutos não armazenados.

$\mathrm{O}$ fato dos frutos armazenados a $8^{\circ} \mathrm{C}$ apresentarem maior germinação e IVG do que aqueles a $-18^{\circ} \mathrm{C}$ está de acordo com Farrant et al. (1988), quando afirmam que sementes "altamente" e "moderadamente recalcitrantes" apresentaram maior tolerância a baixas temperaturas, porém nunca igual ou inferiores a $0^{\circ} \mathrm{C}$. As sementes dos frutos armazenados em congelador apresentaram resultados semelhantes aos deixados em ambiente de laboratório. A diminuição da germinação nos tratamentos de frutos armazenados a $8^{\circ} \mathrm{C}$ e a $-18^{\circ} \mathrm{C}$ pode ser atribuída à sensibilidade das sementes, dessa espécie, a temperaturas baixas. O que também foi verificado pelo tratamento V8 do experimento um (Figura 1). De qualquer maneira, o armazenamento de frutos, em quaisquer das condições estudadas não se mostrou eficiente para preservar a qualidade das sementes.

Nos experimentos um a três (Figuras 4 a 6) as sementes passaram pelo processo de fermentação, como indicaram Carmona et al. (1994), alegando que a presença de mucilagem nas sementes de Campomanesia adamantium, resultou em grande desenvolvimento de fungos. Sendo esta, provavelmente, a principal causa de decréscimo na qualidade de sementes não fermentadas, que pode ser justificado ao fato da mucilagem, intimamente aderida às sementes, poder prejudicar a germinação e o desenvolvimento das plântulas ou conter substâncias inibidoras da germinação.

Os resultados obtidos conduzem a a dedução de que, a mucilagem das sementes de gabiroba não apresenta substâncias inibidoras da germinação pois a germinação das sementes recém extraídas com mucilagem foi acima de $80 \%$ (Figura 3.3). Portanto, melhor do que utilizando o emprego de fermentação, permitindo contestar a necessidade de retirada da mucilagem pelo processo de fermentação.
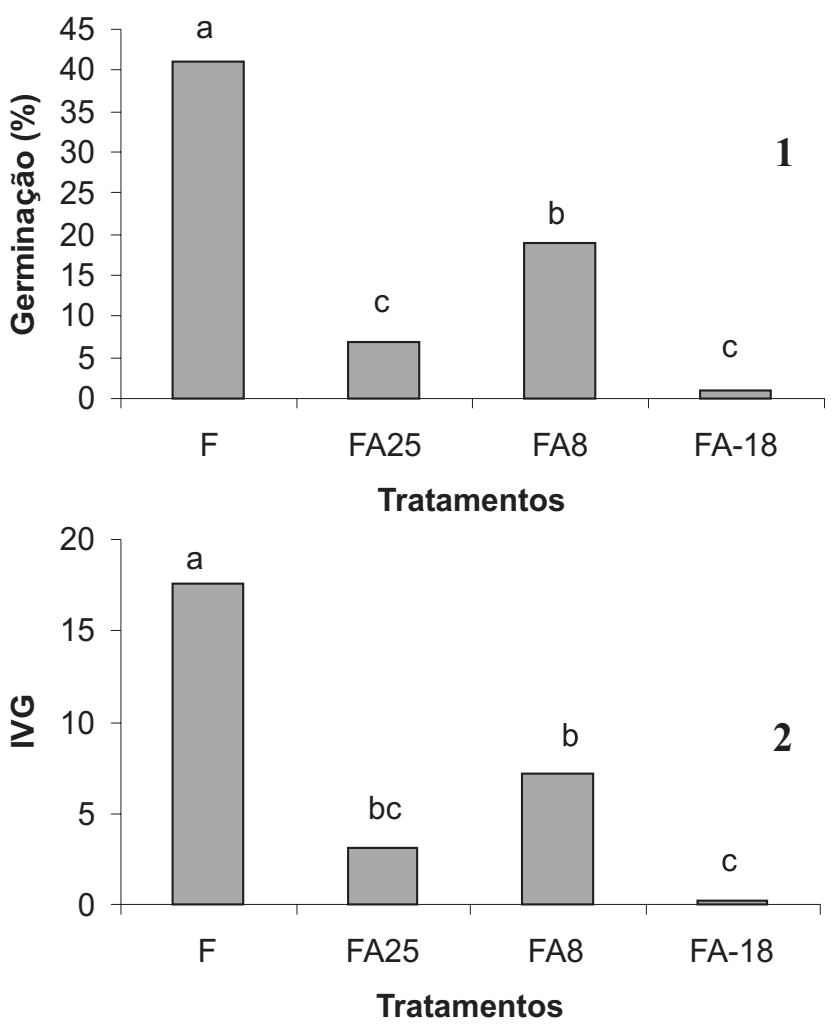

FIGURA 6. Porcentagem de germinação(1) e índice de velocidade de germinação (2) de sementes de gabiroba frescas (F); extraídas de frutos armazenados por 20 dias a $25^{\circ} \mathrm{C}$ (FA25); a $8^{\circ} \mathrm{C}$ (FA8) e a $-\mathbf{1 8}^{\circ} \mathrm{C}$ (FA-18). Presidente Prudente, 2003. Barras seguidas por letras iguais indicam médias sem diferenças significativas, pelo teste Tukey, ao nível de $5 \%$. 


\section{CONCLUSÕES}

O ponto de colheita de frutos de Campomanesia adamantium, para obtenção de sementes, pode ser determinado pela medida do Brix da polpa, sendo indicada a colheita dos frutos com, no mínimo, $15,75^{\circ}$ para se obter $95 \%$ de germinação.

O comportamento das sementes de guabiroba indica que a espécie pode ser classificada como recalcitrante, por não suportar armazenamento a baixa temperatura e ser intolerante à dessecação.

$\mathrm{O}$ armazenamento em frasco de vidro fechado a $25^{\circ} \mathrm{C}$ mantém as sementes com $60 \%$ de germinação, por 30 dias. Todavia, a semeadura logo após a extração dos frutos, permite valores de germinação de, no mínimo, 74\%.

\section{REFERÊNCIAS}

ARRIGONI, B.M.F.; ALVARENGA, A.A.; CARVALHO D.A. Armazenamento e viabilidade de sementes de Campomanesia rufa. Ciência e Agrotecnologia, Lavras, v.21, n.1, p.85-90, 1997.

BORGONOVI, M.; CHIARINI, J.V. Cobertura vegetal do Estado de São Paulo. I - Levantamento por fotointerpretação das áreas cobertas por Cerrado, cerradão e campo. Bragantia, Campinas, v.24, n.14, p.159-172, 1962.

BRASIL. Ministério da Agricultura e Reforma Agrária. Regras para análises de sementes. Brasília: SNDA/DNDV/CLAV, 1992. 365 p.

CARMONA, R.; REZENDE, L.P.; PARENTE, T.V. Extração química de sementes de gabiroba (Campomanesia adamantium Camb.). Revista Brasileira de Sementes, Brasília, v.16, n.1, p.31-33, 1994.

CARVALHO, J.E.U.; LEÃO, N.V.M.; MÜLLER, C.H. Sensibilidade de sementes de gabiroba (Campomanesia lineatifolia Ruiz et Pav. - MYRTACEAE) ao dessecamento e à baixa temperatura. In: CONGRESSO BRASILEIRO DE SEMENTES, 10, 1997, Foz do Iguaçu. Anais... Foz do Iguaçu: ABRATES. v.7, n.1/2, p.252, 1997.

CÍCERO, S.M.; MARCOS FILHO, J.; TOLEDO, F.F. Efeitos do tratamento fungicida e de três ambientes de armazenamento sobre a conservação de seringueira. In: Anais da ESALQ, Piracicaba, v.43, n.2, p.763-787, 1986.

DURIGAN, G.; NISHIKAWA, D.L.L.; ROCHA, E.; SILVEIRA, E.R.; RANIERI, V.E.L. Caracterização de dois estratos da vegetação em uma área de serrado no município de Brotas, SP, Brasil. Acta Botânica Brasileira, São Paulo, v.16, n.3, p.251-262, 2002.

EITEN, G. The Cerrado vegetation of Brazil. Botanical Review,
New York, v.38, n.2, p.201-341, 1972.

FARRANT, J.M.; PAMMENTER, N.W.; BERJAK, P. Recalcitrance: a current assessment. Seed Science and Technology, Zürich, v.16, n.1, p.155-166, 1988.

FONSECA, S.C.L.; FREIRE, H.B. Sementes recalcitrantes: problemas na pós-colheita. Bragantia, Campinas, v.62, n.2, p.297303, 2003.

HOEKSTRA F.A.; GOLOVINA, E.A.; BUITINK, J. Mecanisms of plant desiccation tolerance. Trends in Plant Science, London, v.6, n.9, p.431-438, 2001.

HONG, T.D.; ELLIS, R.M. Optimum air-dry seed storage enviroments for arábica cofee. Seed Science and Tecnology, Zürich, v.20, n.3, p.547-560, 1992.

KRONKA, F.J.N.; NALON, M.A.; MATSUKUMA, C.K.; PAVÃO, M.; GUILlAUMON, J.R.; CAVALLI, A.C.; GIANNOTTI, E.; IWANE, M.S.S.; LIMA, L.M.P.R.; MONTES, J.; DEL CALI, I.H.; HAACK, P.G. Áreas de domínio do Cerrado no Estado de São Paulo. São Paulo: Secretaria do Estado do Meio Ambiente/Instituto Florestal, 1998. 84p.

LEITÃO FILHO, H.F.; MARTINS, F.R. Espécies de Cerrado com potencial em fruticultura. In: CONGRESSO ANUAL DA SOCIEDADE AMERICANA DE CIÊNCIAS HORTÍCOLAS, 29, 1981, Campinas. Anais... Campinas: ASHS, 1981. p.29.

MALUF, A.M.; BILIA, D.A.C.; BARBEDO, C.J. Drying and storage of Eugenia involucrata DC. seeds. Scientia Agricola, Piracicaba, v.60, n.3, p.471-475, 2003.

NAKAGAWA, J. Testes de vigor baseados nos desempenhos das plântulas. In: KRZYZANOWSKI, F.C.; VIEIRA, R.D.; FRANÇA NETO, J.B. (eds). Vigor de sementes: conceitos e testes. Londrina: ABRATES, 1999. p.2.1-2.24.

PARENTE, T.V.; MACHADO, J.W.B. Aspectos fenológicos de fruteiras nativas do Cerrado do Distrito Federal em condições de cultivo. In: CONGRESSO BRASILEIRO DE FRUTICULTURA, 10, 1989, Fortaleza. Anais... Fortaleza: SBF, 1989a. p.487-492.

PARENTE, T.V.; MACHADO, J.W.B. Comportamento de cinco espécies de frutíferas nativas do Cerrado do Distrito Federal em condições de cultivo. In: CONGRESSO BRASILEIRO DE FRUTICULTURA, 10, 1989, Fortaleza. Anais... Fortaleza: SBF, 1989b. p.498-504.

ROBERTS, E.H. Predicting the storage life of seeds. Seed Science and Tecnology, Zürich, v.1, n.2, p.499-514, 1973.

SÃO PAULO/SECRETARIA DO ESTADO DO MEIO AMBIENTE. Bases para conservação e uso sustentável das áreas de Cerrado do Estado de São Paulo. São Paulo, 1997. 113p.

SILVA, J.A.; SILVA, D.B.; JUNQUEIRA, N.T.V.; ANDRADE, L.R.M. Frutas nativas dos Cerrados. Brasília: EMBRAPA, 1994. 166p. 